\title{
JFK Coma Recovery Scale-Revised Clinical Classification
}

National Cancer Institute

\section{Source}

National Cancer Institute. IFK Coma Recovery Scale-Revised Clinical Classification. NCI

Thesaurus. Code C124711.

A standardized rating scale developed by Giacino et al in 1991, and modified and further characterized by Giacino et al in 2004, which is a classification system used to assist with differential diagnosis, prognostic assessment and treatment planning in patients with disorders of consciousness. This instrument contains 6 subscales addressing auditory, visual, motor, oromotor, communication, and arousal processes. 